\title{
Residual Constitutive Behavior of Aluminum Alloys after Fire Exposure
}

\author{
PATRICK SUMMERS ${ }^{1}$, BRIAN LATTIMER ${ }^{1},{\text { SCOTT } \text { CASE }^{2}}^{2}$ \\ ${ }^{1}$ Department of Mechanical Engineering \\ ${ }^{2}$ Department of Engineering Science \& Mechanics \\ Virginia Polytechnic Institute \& State University \\ Blacksburg, VA 24061, USA
}

\begin{abstract}
Aluminum alloys are increasingly being used in lightweight transportation applications such as naval vessels and light passenger rail. The aluminum alloys considered include 5xxx-series ( $\mathrm{Al}-\mathrm{Mg})$ and $6 \mathrm{xxx}-$ series (Al-Mg-Si) alloys due to their mechanical strength, corrosion resistance, and weldability. A major concern in the use of aluminum alloys in lightweight structural applications is fire exposure. Aluminum mechanical properties are significantly reduced at $300^{\circ} \mathrm{C}$. After fire exposure, structural damage will vary due to the local thermal history which is governed by the fire size and proximity and other environmental factors. It is paramount to understand the nature of this structural damage in terms of residual (post-fire) constitutive behavior so as to allow for informed damage assessment.
\end{abstract}

AA5083-H116 and AA6061-T651 residual constitutive behavior was characterized using quasi-static tension tests. The alloys were exposed to elevated temperatures at controlled heating rates using an induction heater to simulate the varying conditions in a fire environment. The thermal history dependence of residual constitutive behavior was elucidated in terms of the microstructural strengthening mechanisms. The primary strengthening mechanisms of AA5083 and AA6061 evolve at elevated temperatures due to recrystallization and precipitate coarsening, respectively. Strengthening mechanism evolution has been shown to be kinetically dependent which explains the thermal history dependence of residual constitutive behavior. Structural damage from a wide range of fire scenarios may be understood using these underlying strengthening mechanisms which govern residual constitutive behavior.

KEYWORDS: structural response, post-fire, residual, constitutive behavior, aluminum

\section{INTRODUCTION}

Aluminum alloys are being increasingly used in load-bearing structures across a broad spectrum of applications. This includes land-based structures, such as transportable temporary housing, and land-based and naval transportation applications such as light rail, passenger airliners, ferries, and military naval vessels. In this sense, and considering the constant push to increase the fuel efficiency and performance in these applications, aluminum has seen widespread use in the past decade with only a growing potential for use in future applications. Some of the numerous drivers of this increased interest in aluminum are the improved corrosion resistance and high specific strength $\left(80 \mathrm{kPa}-\mathrm{m}^{3} / \mathrm{kg}\right)$ as compared to steel $(55 \mathrm{kPa}-$ $\mathrm{m}^{3} / \mathrm{kg}$ ). Alloys are typically selected based on application; 5xxx-series (Al-Mg) and 6xxx-series (Al-Mg$\mathrm{Si}$ ) are typically used in naval applications due their desirable combination of mechanical strength, corrosion resistance, and weldability.

A major concern in the use of aluminum alloys in structural, load-bearing applications is fire exposure. Aluminum mechanical properties degrade at temperatures as low as $150^{\circ} \mathrm{C}$ and suffer a $50 \%$ reduction at approximately $275^{\circ} \mathrm{C}$ [1]. This significant effect of fire on the load-carrying capability of an aluminum structure at relatively low temperatures (compared to the fire environment) requires careful consideration and design for fire. This includes ensuring the structural survivability is such to allow for human egress and fire extinguishment. In support of this, aluminum elevated temperature constitutive behavior has been extensively researched and reported in Eurocode 9 [2] as it pertains to fire in structural applications.

Aluminum structural fire design that includes protective measures, such as ceramic fiber insulation and fire barriers, can only be relied upon to a certain extent. For example, installed insulation may not withstand the turbulent and violent fire environment in an internal compartment. Installation of fire insulation also cannot be expected on all exposed structural surfaces, especially in lightweight transportation applications. Therefore, the potential exists for an aluminum structure to experience varying indirect and direct exposure 
to the fire environment. The structure may endure a range of thermal exposures based on fire size, proximity, the existence of fire insulation, and other environmental factors. The surviving structure, after returning to ambient conditions, may therefore have a wide range of post-fire (residual) damage depending on local thermal exposure (history).

The post-fire structural damage may range from unaffected to severely deteriorated mechanical properties all the way to burn-through caused by direct flame impingement, etc. This assertion is reinforced by Matulich [3] who studied the effects of prior thermal exposure on yield strength and Vickers hardness. In that study, aluminum previously exposed to $300^{\circ} \mathrm{C}$ was found to undergo a $50 \%$ reduction in yield strength. The yield strength was also unaffected until about $200^{\circ} \mathrm{C}$ and underwent further reduction up to $500^{\circ} \mathrm{C}$. It is therefore important to consider the entire fire-exposed structure, not only severely damaged areas, e.g., due to fire holing, when assessing the post-fire load-carrying capability. The post-fire damage also does not operate in a boolean fashion, but varying damage levels are attained based on prior thermal exposure. In this sense, post-fire aluminum structural damage must be assessed using methods and standards independent of those classically used for steel structures which simply consider visibly damaged sections for repair or replacement.

As discussed, a necessary component of aluminum structural survivability in fire is to understand how the fire environment damages the structure after it has returned to ambient conditions. A fundamental understanding of damage, defined as reduced mechanical properties, allows for intelligent repair of damaged structures in a cost effective and timely fashion. A broad spectrum of fire scenarios exist with varying heating rates, maximum temperatures, and soak times. Therefore, it would be exceedingly advantageous to develop this understanding in reference to the governing mechanisms to allow for its application outside of the specific conditions at which the residual constitutive behavior was quantified. For aluminum alloys, this would be in terms of the microstructural strengthening mechanisms which are modified during material processing to impart the desired mechanical properties.

Limited data is currently available in the literature regarding the residual constitutive behavior of aluminum alloys after fire exposure. Matulich [3] qualitatively investigated the residual yield strength and Vickers hardness of 5xxx and $6 \mathrm{xxx}$-series alloys as a function of maximum exposure temperature and soak time. The residual properties were qualitatively shown to be dependent on the time-temperature thermal exposure. The residual behavior of steels has also been lightly researched. Qiang, et al. [4] investigated high strength steels, focusing on development of empirical correlations for residual mechanical properties as a function of exposure temperature. Currently, the literature contains no studies researching residual aluminum constitutive behavior in terms of the evolution of the governing microstructural strengthening mechanisms. It is the primary goal of the presented research to fill this literature gap thereby providing a fundamental understanding of damaged aluminum structures after fire.

In this research, AA5083-H116 and AA6061-T651 aluminum alloys were characterized to determine their residual constitutive behavior. The alloys were exposed to temperatures up to $500^{\circ} \mathrm{C}$ using an induction heater at controlled heating rates of 5,25 , and $250^{\circ} \mathrm{C} / \mathrm{min}$. Quasi-static, uniaxial tension tests were performed to quantify the residual constitutive behavior and mechanical properties. Special attention was given to analysis of the residual constitutive behavior in terms of thermal history so as to understand how it is kinetically (time-temperature) dependent. The primary microstructural strengthening mechanisms were investigated using microscopy and a thorough review of the literature which is well-developed on the topic. Through the microstructural strengthening mechanisms, the governing mechanisms were elucidated and the thermal history dependence of AA5083-H116 and AA6061-T651 residual constitutive behavior was determined.

\section{EXPERIMENTAL DETAILS}

\section{Materials and Specimen Geometry}

Two aluminum alloys were investigated in this research: AA5083-H116 and AA6061-T651. AA5083 is an $\mathrm{Al}-4.9 \mathrm{wt} \% \mathrm{Mg}$ alloy strengthened by strain-hardening (cold-work). It is a weldable, moderate strength alloy which exhibits good corrosion resistance in the H116 condition. AA6061 is an Al-1.2wt\%Mg$0.8 \mathrm{wt} \% \mathrm{Si}$ alloy strengthened precipitation-hardening (heat treatment). It is a weldable, high strength alloy 
which also exhibits good corrosion resistance. The characteristics of both alloys make them excellent candidates for use in lightweight structural applications.

Flat dog-bone specimens for mechanical testing were machined from the as-received plate with the longitudinal axis oriented along the rolling direction. The specimens had an overall length of $169.2 \mathrm{~mm}$ and a gage length and width of 50.8 and $12.7 \mathrm{~mm}$, respectively. Specimen thickness was unchanged from the as-received plate thickness -6.4 and $6.5 \mathrm{~mm}$ for AA5083 and AA6061, respectively.

\section{Non-isothermal Heating}

The residual constitutive behavior of the alloys will be investigated by varying the prior thermal history due to simulated fire exposure. The specimens were thermally exposed prior to mechanical testing using constant, linear heating rate exposures to a range of prescribed temperatures. This type of exposure was selected primarily to isolate and analyze the factors influencing material evolution. Additionally, a constant heating rate is a good approximation of the initial transient portion during fire exposure. The heating rates were selected based on a representative aluminum structural section subjected to the UL 1709 [1] standard fire resistance test. The UL 1709 time-temperature exposure is intended to represent the rapid temperature rise of hydrocarbon fires and subjects test articles to incident heat fluxes of approximately 200 $\mathrm{kW} / \mathrm{m}^{2}$. The commercial finite element code Abaqus was used to model the transient thermal response of a representative aluminum section (4 $\mathrm{mm}$ thickness). The aluminum section was modeled with no insulation and with 25.4 and $50.8 \mathrm{~mm}$ thick ceramic fiber insulation (Superwool 607). The predicted transient heating of the material surface is shown in Fig. 1. The section's effective heating rate was calculated as the heating rate from test start to a temperature corresponding to $50 \%$ of the steady-state temperature. Using this criterion, the effective heating rates for no insulation and 25.4 and $50.8 \mathrm{~mm}$ thick insulation were calculated as 250,25 , and $5^{\circ} \mathrm{C} / \mathrm{min}$, respectively.

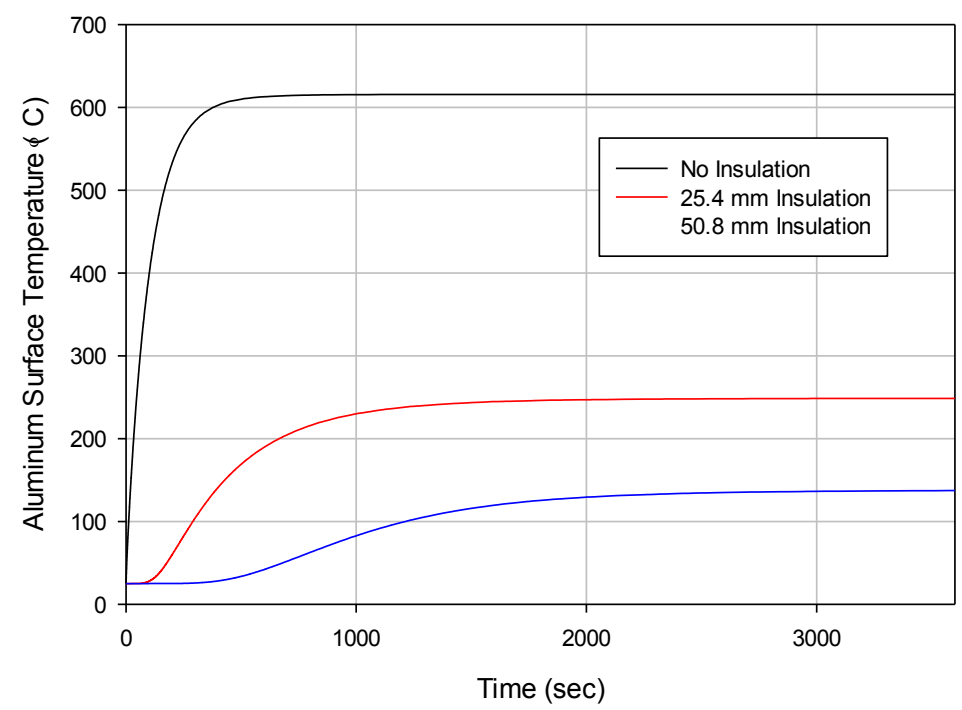

Fig. 1. Transient heating predictions of a representative aluminum structural section exposed to the UL 1709 standard fire exposure.

The specimens were thermally exposed at the desired constant, linear heating rates using the induction heater shown in Fig. 2a. The specimens were heated to prescribed temperatures up to $500^{\circ} \mathrm{C}$ at which point the specimens were immediately quenched in water thereby arresting material evolution. The induction heater was controlled using a Micro-Epsilon optical pyrometer $(8-14 \mu \mathrm{m}$ spectral range) and a Watlow PID controller. An optically-thick layer of high-temperature flat black paint was deposited on the surface to ensure constant, unvarying temperature measurement. The temperature-dependent paint emissivity was used to ensure accurate temperature control using the pyrometer. Heating of the specimen was monitored using a FLIR SC655 (7.5 - $14 \mu \mathrm{m}$ spectral range) thermal camera, also providing measurement of the temperature profile along the specimen gage length. 


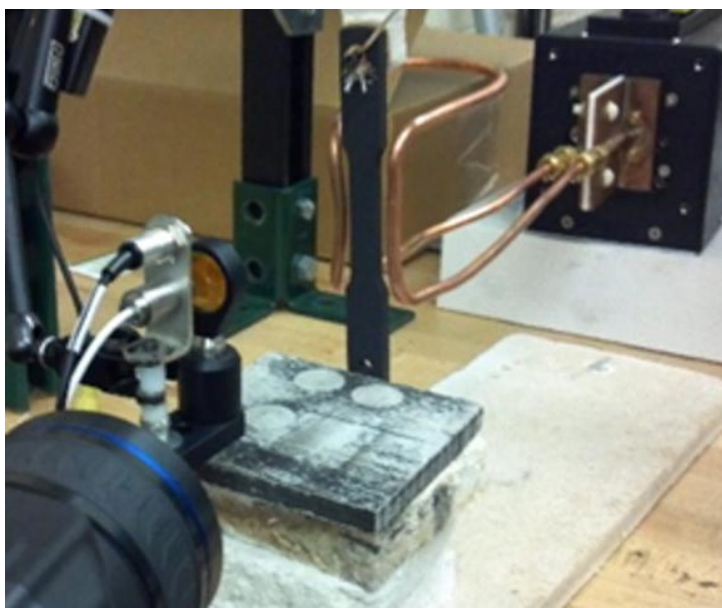

(a)

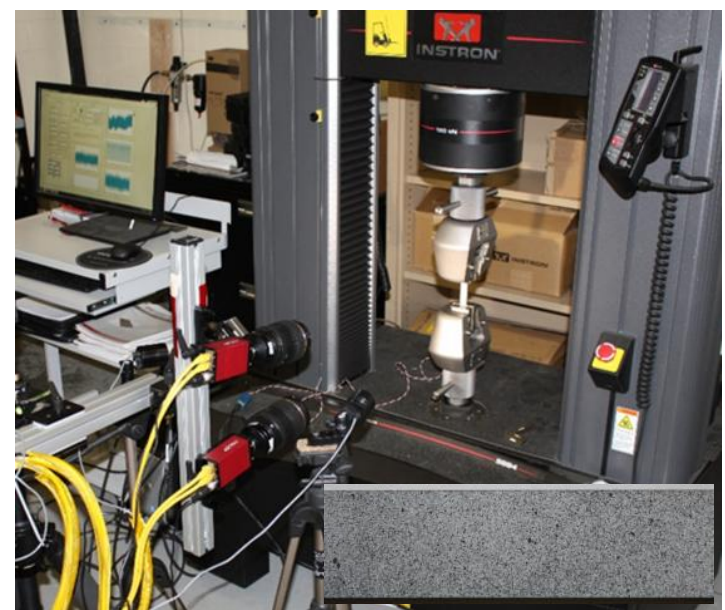

(b)

Fig. 2. Experimental setup: (a) induction heater and (b) mechanical testing machine.

\section{Mechanical Testing}

Monotonic, uniaxial, tensile mechanical tests were performed to evaluate residual constitutive behavior after simulated fire exposure. These tests were performed using an Instron 5984 electro-mechanical testing machine equipped with a $150 \mathrm{kN}$ load cell. All tests were performed with an initial strain rate of $10^{-3} / \mathrm{s}$.

Strain was measured using two methods: strain gages and digital image correlation (DIC). The strain gages used were Vishay Micro-Measurements CEA-13-125UW-350 gages with grid (gage) lengths of $3.175 \mathrm{~mm}$. The strain gages were adhered to the specimen surface using Vishay Micro-Measurements M-Bond 200 adhesive. The gages remained adhered to the surface until strains of approximately $0.015-0.02$.

The Correlated Solutions DIC system (Fig. 2b) used in this study is a stereoscopic, non-contact strain measurement system capable of measuring three-dimensional strains. The system comprises two 2.2 megapixel CCD cameras capable of imaging the specimen at up to 60 frames per second (fps). In this study, images were taken at $30 \mathrm{fps}$ during the initial 60 seconds of the test and $2 \mathrm{fps}$ after that until after specimen rupture. The images are taken at a higher rate at the beginning of the test to increase data in the elastic region and during material yielding. A stochastic speckle pattern was applied to the test specimens as shown in the inset in Fig. 2b. A high temperature flat black spray paint was used to apply the speckle pattern as it was shown to provide better ductility and less cracking at the high strains experienced prior to specimen rupture.

\section{EXPERIMENTAL RESULTS}

The residual constitutive behavior of AA5083-H116 and AA6061-T651 at select temperatures is shown in Figs. 3a-b and 3c-d, respectively. The complete engineering stress-strain relations measured using DIC up to fracture are shown in Figs. 3a,c. The engineering stress-strain relations measured using strain gages at small strains are shown in Figs. 3b,d. The strain gage measurements allow for accurate quantification of the residual yield behavior evolution.

The residual constitutive behavior evolution of the alloys are considerably different. AA5083 exhibits significant hardening after yielding resulting in ultimate stresses significantly higher than yield. Minor localization (necking) occurs as signified by the relatively small strains after reaching the ultimate stress. The stepping behavior of the AA5083 stress-strain relations are caused by serrated yielding, as known as the Portevin-Le Chatelier (PLC) effect. This behavior is common in solution-hardened alloys such as AA5083. An important aspect of the residual constitutive behavior is that the hardening behavior is relatively unchanged as a function of prior thermal exposure. This signifies that the microstructure affecting plastic behavior is relatively unaffected during thermal exposure. AA6061, however, exhibits a significant evolution in residual constitutive behavior after thermal exposure. Minor material hardening is measured for exposures at or below $200^{\circ} \mathrm{C}$. The hardening rate $(d \sigma / d \varepsilon)$, where $\sigma$ and $\varepsilon$ are engineering stress and strain, respectively, significantly increases as a function of increasing exposure temperature. 
Also, unlike AA5803, AA6061 exhibits significant localization (necking). Additionally, as is observed in Figs. $3 \mathrm{~b}, \mathrm{~d}$, the elastic modulus is unchanged as a function of thermal exposure. The calculated average elastic moduli for AA5083-H116 and AA6061-T651 are 70.4 and 69.2 GPa, respectively.

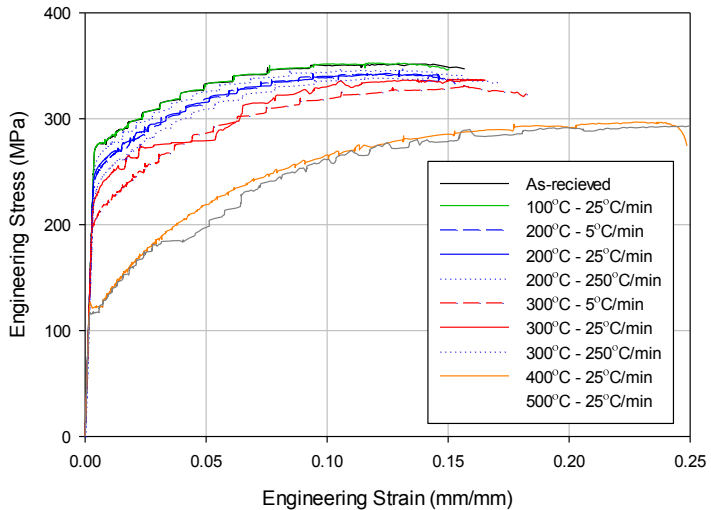

(a)

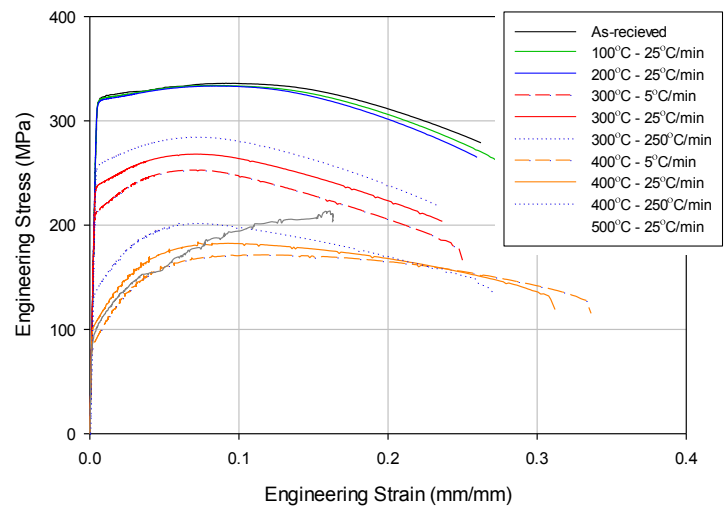

(c)

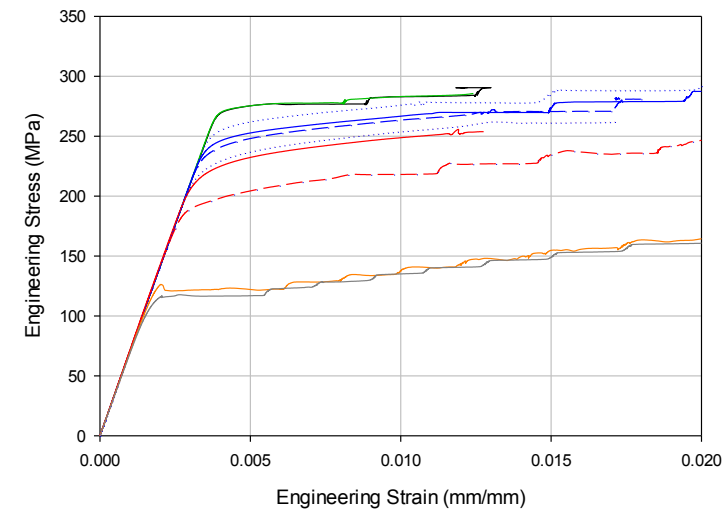

(b)

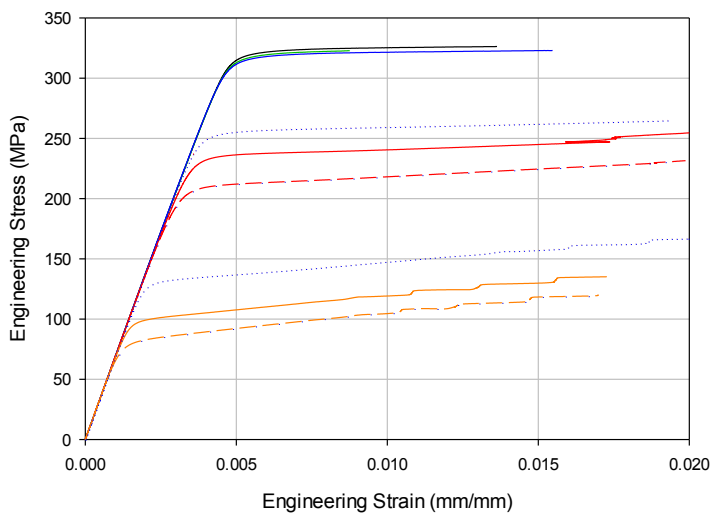

(d)

Fig. 3. Engineering stress-strain relations for (a)-(b) AA5083-H116 and (c)-(d) AA6061-T651.

The residual yield strength was calculated using the $0.2 \%$ strain offset method. Fig. 4 a shows the residual yield strength of AA5083-H116 and AA6061-T651 as a function of exposure temperature. The AA6061 residual yield strengths are largely unaffected below $200^{\circ} \mathrm{C}$ while AA5083 exhibits a slight reduction from 100 to $200^{\circ} \mathrm{C}$. Both alloys experience a significant reduction in yield strength from 200 to $400^{\circ} \mathrm{C}$, at which point the minimum yield strengths are attained. AA5083 reaches approximately the same minimum yield strength $(120 \mathrm{MPa})$ regardless of heating rate. However, AA6061 maintains a dependence on heating rate with a minimum of $87 \mathrm{MPa}$ attained at $5^{\circ} \mathrm{C} / \mathrm{min}$. The residual ultimate stresses are also shown in Fig. $4 \mathrm{~b}$. This mechanical property is revealing as to the evolution of the alloy's hardening capacity after thermal exposure. AA5083 is not significantly affects by thermal exposure; however, AA6061 experiences a significant evolution in terms of ultimate stress, reaching a minimum at 400C. The residual ultimate stress evolution is verified by the residual constitutive behavior shown in Figs. $3 \mathrm{a}$ and $2 \mathrm{c}$, respectively.

The residual ductility was quantified using reduction in area after specimen fracture. The percent reduction in area is shown as a function of exposure temperature in Fig. 5. Fracture images are also shown in Fig. 6 to illustrate localization and fracture behavior. AA5083 experiences ductile shear fracture with insignificant localization prior to fracture in the as-received state. An increase in localization was measured after exposure to $400^{\circ} \mathrm{C}$. AA6061 exhibited ductile cup-in-cone fracture for all exposure temperatures. A significant amount of localization occurs prior to fracture, increasing at exposure temperatures above $200^{\circ} \mathrm{C}$. A slight decrease in reduction in area was measured for specimens exposed at $500^{\circ} \mathrm{C}$. 


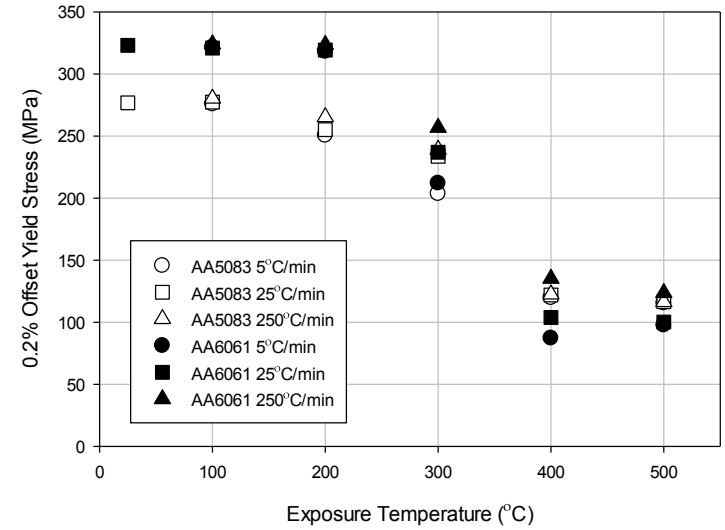

(a)

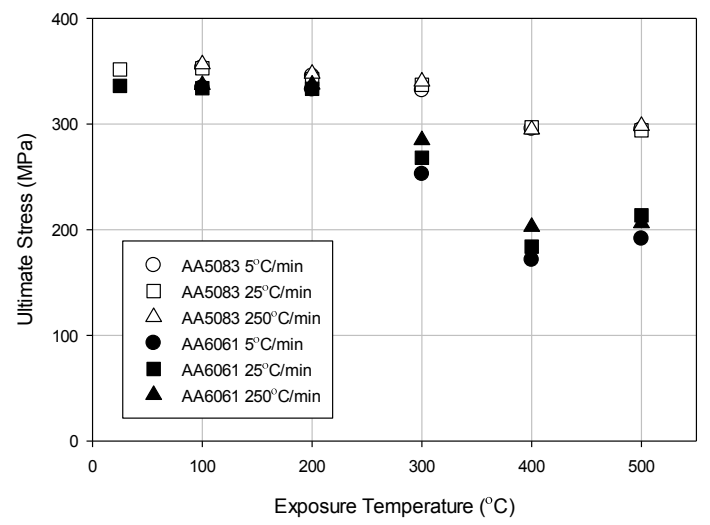

(b)

Fig. 4. Residual mechanical properties: (a) $0.2 \%$ offset yield stress and (b) ultimate stress.

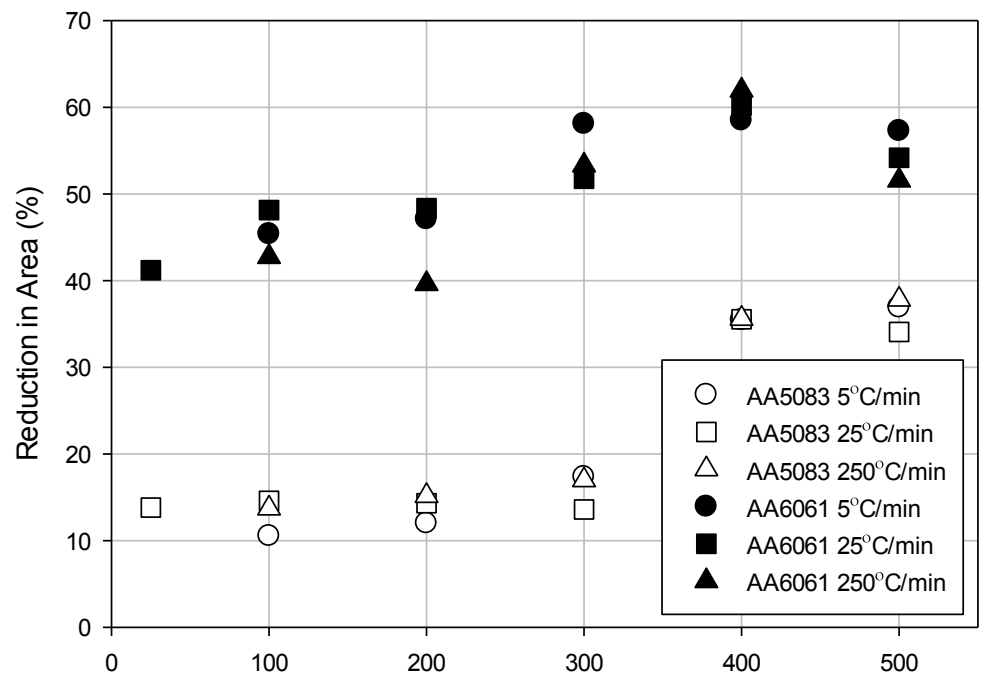

Exposure Temperature $\left({ }^{\circ} \mathrm{C}\right)$

Fig. 5. Reduction in area as a function of exposure temperature.

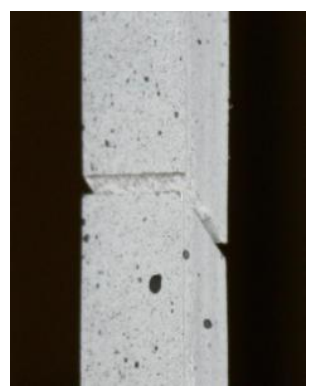

(a)

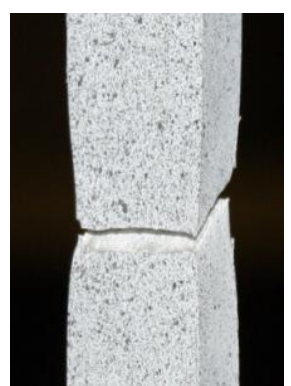

(b)

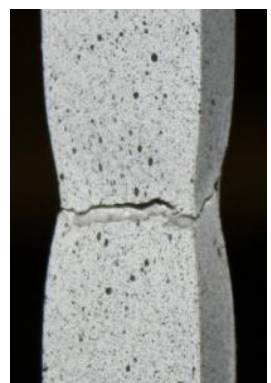

(c)

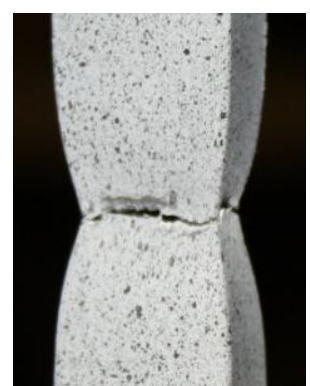

(d)

Fig. 6. Fracture images of (a),(c) as-received and (b),(d) previously exposed $\left(400^{\circ} \mathrm{C}\right.$ at $\left.25^{\circ} \mathrm{C} / \mathrm{min}\right)$ (a),(b) AA5083-H116 and (c),(d) AA6061-T651. 


\section{DISCUSSION AND ANALYSIS}

\section{Residual Constitutive Behavior Dependence on Prior Thermal Exposure}

Constant heating rate exposures of 5,25 , and $250^{\circ} \mathrm{C} / \mathrm{min}$ were used to simulate several fire scenarios. The heating rates were selected based on the UL 1709 standard fire resistance test applied to a representative aluminum structure. The heating rates were specifically calculated using a thermal model to predict the transient thermal response of the structure with and without ceramic fiber insulation. Additionally, the wide variation in heating rates is by definition representative of a wide variation of fire scenarios. This is important considering the variety of possible fire scenarios result in a wide range of heating rates, maximum temperatures, and soak times. In this manner, the selected heating rates are representative of the expected transient response of aluminum structures for a wide range of expected fire scenarios.

The residual constitutive behavior of the aluminum alloys investigated in this study, AA5083-H116 and AA6061-T651, exhibited different evolutions in terms of prior thermal exposure (Fig. 3). This difference is primarily derived from the manner in which the alloys are strengthened. The effect of this will be discussed in detail in the subsequent section. The most noticeable difference is the manner in which the varying heating rate affects residual constitutive behavior evolution. AA6061 constitutive behavior has a significant heating rate dependence at exposures above $200^{\circ} \mathrm{C}$. Consequently, the specific fire exposure will have a significant effect on the residual constitutive behavior, including properties. In contrast, AA5083 constitutive behavior only exhibits on a significant heating rate dependence between 300 and $400^{\circ} \mathrm{C}$. Also of note, the AA5083 plastic capacity, in terms of hardening rate $(d \sigma / d \varepsilon)$ and ultimate stress, is relatively independent of thermal history, including both heating rate and maximum exposure temperature. In comparison, the plastic capacity of AA6061 exhibits dependence on both heating rate and exposure temperature. This relative dependence signifies that the alloy's strengthening mechanisms contribute substantially to the evolution of the residual constitutive behavior.

\section{Microstructural Strengthening Mechanism Evolution}

Aluminum alloys attain their strength through the relative state of their microstructural strengthening mechanisms, e.g., grain boundaries, which inhibit dislocation movement. The material processing methods used for AA5083-H116 and AA6061-T651, cold-work and heat treatment, respectively, develop and/or evolve these microstructural mechanisms to obtain the desired constitutive behavior. Likewise, it is the further evolution of these mechanisms which governs residual constitutive behavior after fire exposure. Mechanical testing (Fig. 3 and Fig. 4) has shown residual constitutive behavior depends on prior thermal exposure, including heating rate and maximum exposure temperature. The nature of this dependence was also shown to be alloy-dependent. This is due to different microstructural strengthening mechanisms in the alloys - solutes and grain refinement for AA5083 and nanoscale precipitates for AA6061. Evolution of these respective mechanisms explains the alloy-based variation of thermal exposure dependence. In this section, evolution of each alloy's microstructural strengthening mechanisms will be discussed to gain insight and explain residual constitutive behavior.

\section{AA5083-H116 Microstructural Evolution}

AA5083-H116 is an Al-Mg alloy strengthened by strain hardening. Huskins, et al. [5] investigated the microstructural strengthening mechanisms in Al-Mg alloys (AA5083-H131). The strengthening mechanisms - solutes, precipitates, and mechanisms due to grain refinement, i.e., grain boundaries (GBs) and sub-grain boundaries (SGBs) - were discussed. The primary strengthening mechanisms of the alloy are solid-solution (solute) hardening and grain refinement. Huskins calculated the strengthening contributions of these mechanisms as 90 and $138 \mathrm{MPa}$ of the yield stress (283 MPa), respectively.

Solid-solution hardening strengthens through a solid solution of either interstitial or substitutional solute atoms in the lattice structure. In AA5083, the larger Mg atoms exist as substitutional solute atoms in the solvent Al lattice. The solutes are point defects in the lattice and act as obstacles to dislocation motion. At small strains, the solute-dislocation interaction strengthens the alloy [5]. The strengthening results from flexible dislocations bending around the high interaction energy solute atom after advancing through the lattice. However, the remainder of the dislocation is free to advance to lower energy positions [6]. The 
"pinning" of dislocation at solutes strengthens by the effective line tension this creates on the dislocation [7]. This strengthening mechanism is primarily responsible for the significant AA5083 work-hardening capacity (Fig. 3a). The strengthening interaction is removed as the mobile solute atom diffuses into the dislocation [5]. The cyclic interaction of mobile solutes and dislocations manifests itself as dynamic strain aging (DSA) in aluminum alloys, which is the time-dependent diffusion of solutes into dislocations. This phenomena is observed macroscopically as serrated yielding in the stress-strain relations (Fig. 3a). The pronounced stress drops occur when the dislocations break free of solutes or solute clusters [8]. In the aggregate, solid-solution hardening significantly contributes to the AA5083 yield strength.

Solid-solution hardening contributes significantly to AA5083-H116 yield strength. However, the $\mathrm{Mg}$ content in solid solution is insignificantly affected above $300^{\circ} \mathrm{C}$ which corresponds to temperatures where significant changes in residual constitutive behavior occur (Figs. 3a,b and Fig. 4) [9]. It is well known at recrystallization affects grain morphology at higher temperatures, such as those associated with the significant reduction in yield stress (Fig. 4a) [10]. Sandstrom and Lindgren [11] determined recrystallization is the most important microstructural process affecting constitutive behavior after high temperature annealing of a commercially-pure aluminum alloy. This is significant as recrystallization, which is the process of grain morphology evolution, affects the strengthening mechanisms developed through grain refinement.

The material processing method of strain-hardening (cold-working) is used to strengthen AA5083-H116 by grain refinement by developing a textured, elongated grain structure with internal sub-grains. Grain boundaries (GBs) and sub-grain boundaries (SGBs) strengthen the alloy by acting as obstacles to dislocation motion. GBs are defined as the boundary of adjacent regions (grains) with significant angles in lattice orientation. This misorientation angle requires additional energy for dislocations to diffuse across the GB thereby strengthening the material. SGBs are high density dislocation entanglements resulting from strain-hardening. Dislocations coalesce after cold-work to form walls thereby dividing the grain into subgrains which are characterized by a slight misorientation of the lattice structure internal to the grain [6]. The strengthening contribution of GBs is typically calculated using the empirical Hall-Petch relationship. SGB strengthening cannot be calculated using Taylor hardening due to the heterogeneous nature of the dislocation structures. In fact, given the nature of the sub-grains, the strengthening may be assumed to occur similar to but weaker than GBs [12]. Therefore, SGB strengthening is typically calculated using Hall-Petch-type relation [6]. The Hall-Petch relation for yield stress contribution for both GBs and SGBs is

$\Delta \sigma_{y}=k_{y} d^{-1 / 2}$

where $\Delta \sigma_{y}$ is the yield stress contribution (MPa), $k_{y}$ is the Hall-Petch constant $\left(\mathrm{MPa}-\mathrm{m}^{1 / 2}\right)$, and $d$ is the average grain size (m). Last and Garrett [12] estimated $k_{y}=0.22 \mathrm{MPa}-\mathrm{m}^{1 / 2}$ for an $\mathrm{Al}-4 \mathrm{wt} \% \mathrm{Mg}$ alloy. The Hall-Petch constant for SGB strengthening is typically be estimated as $0.2-0.5$ of that for the macroscopic alloy. Huskins, et al. [5] empirically determined this as $0.064 \mathrm{MPa}-\mathrm{m}^{1 / 2}$ for the studied AA5083-H131. Substituting these constants in Eq. 1, GB and SGB strengthening contributions were calculated as 25 and $113 \mathrm{MPa}$, respectively. Thus the primary strengthening mechanism is the sub-grains internal to the grains.

Recrystallization is defined as the formation a new grain structure in a deformed material by the nucleation and migration of GBs by the stored energy of deformation [10]. Recrystallization, therefore, is a physical process in which energy, in this case thermally, is added to a system to cause transition to a lower energy state. The effect of recrystallization on AA5083-H116 grain morphology is shown in Fig. 7. The textured grain structure in the as-received condition (Fig. 7a) is elongated in the rolling direction. Recrystallization destroys the as-received texture forming an equiaxed grain structure (Fig. 7b). The smaller, equiaxed recrystallized grain structure is energetically favorable as compared to the textured, elongated grain structure developed during strain hardening. Grain sizes were estimated using the line-intercept method for an anisotropic material according to ASTM E112 [13]. The average grain sizes were estimated in the asreceived and recrystallized conditions as 89.1 and $48.2 \mu \mathrm{m}$, respectively. The Hall-Petch relation (Eq. 1) estimates the strengthening contribution of these grain sizes as 23.3 and $31.7 \mathrm{MPa}$, respectively. 


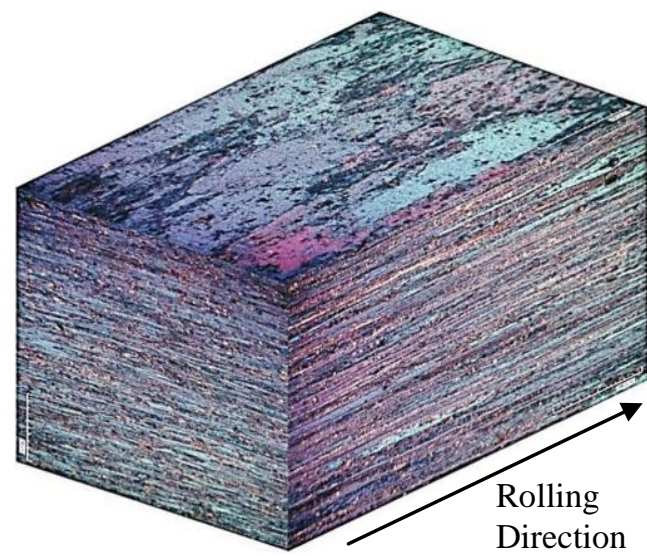

(a)

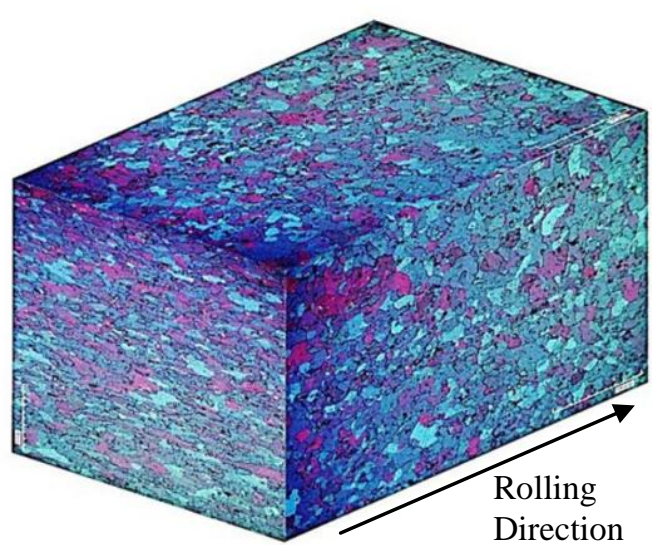

(b)

Fig. 7. AA5083-H116 grain morphology (a) as-received and (b) recrystallized after $400^{\circ} \mathrm{C}$ exposure.

The sub-grain boundaries, not the grain boundaries, are the primary strengthening mechanism in AA5083 [5]. The reduction in AA5083-H116 yield strength (Fig. 4a) may be assumed to be due to sub-grain evolution during recrystallization given the discussed strengthening contributions of solutes (unchanged above $300^{\circ} \mathrm{C}$ ) and grain boundaries ( 8 $\mathrm{MPa}$ increase). The dislocation sub-structures (SGBs) which segregate the sub-grains are shown for as-received AA5083-H116 in Fig. 8. The average distance between SGBs $(376 \mathrm{~nm})$ was determined using the line-intercept method. The evolution of the sub-grains at elevated temperatures is governed by recrystallization. As a recrystallized grain grows from its nucleation site, dislocations in its path are annihilated, including the dislocation entanglements comprising SGBs [6]. Thus, the primary strengthening mechanism in AA5083-H116, sub-grain boundaries, is destroyed during recrystallization.

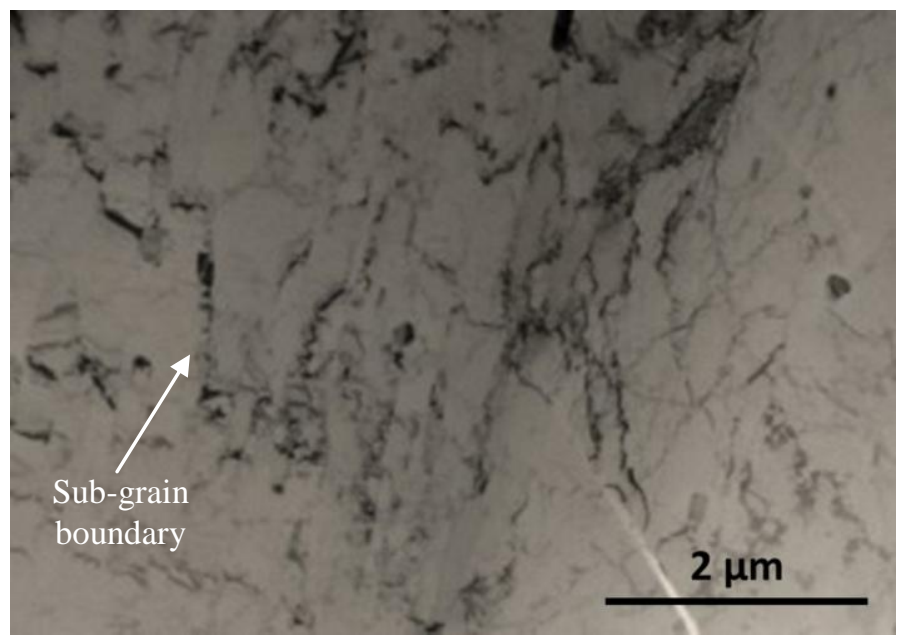

Fig. 8. TEM micrograph of AA5083-H116 sub-grain structure.

It is especially important in this work to understand recrystallization evolution in order to understand the impact of thermal history on the residual constitutive behavior. Recrystallization is a thermally-activated microstructural process driven by the release of stored energy from strain hardening. Kwon and DeArdo [14] found that the residual constitutive behavior of a commercial-purity alloy is a function of pre-strain (due to cold-work), annealing temperature, and annealing time. Property reduction followed a sigmoidal relationship with no inflections, indicating recrystallization occurs independently of other microstructural processes. The property reduction was also shown to be kinetically-related to the recrystallized fraction by a sigmoidal relationship with annealing time. Vandermeer and Jensen [15] investigated the kinetics of recrystallization in $90 \%$ cold-rolled AA1050. The activation energy $(172-183 \mathrm{~kJ} / \mathrm{mol})$ indicated that a solute-limited boundary migration rate mechanism was controlling grain growth. Additionally, the 
recrystallization morphology evolution was found to be isokinetic, i.e., identical for all studied annealing temperatures.

The evolution of AA5083-H116 residual constitutive behavior as a function of thermal history is explained through the microstructural evolution. The microstructural strengthening mechanisms contributing to material strength are solid-solution hardening, grain boundaries, and sub-grains boundaries. The solidsolution hardening contributes significantly to work-hardening capacity which is largely unaffected at elevated temperatures as shown in Fig. 3a. The primary strengthening mechanism-sub-grain boundaries - is significantly affected by recrystallization at temperatures above $250^{\circ} \mathrm{C}$. This is reflected by the severe reduction in yield strength from $250-350^{\circ} \mathrm{C}$. The kinetics of recrystallization as detailed in [14], [15] are also reflected in the residual constitutive behavior in Figs. 3a,b and Fig. 4. The heating rate dependent yield strength measured after exposure to $300^{\circ} \mathrm{C}$ supports this assertion.

In summary, AA5083-H116 residual constitutive behavior after elevated temperature exposure is governed by grain morphology. Recrystallization is the microstructural process by which the grain morphology at elevated temperatures. It is this evolution which annihilates the sub-grain boundaries, which are the primary strengthening mechanism in the alloy. The destruction of the sub-grains is the underlying mechanism responsible for the yield strength reduction at temperature corresponding to recrystallization. Recrystallization was also shown to be thermally history (kinetically) dependent, which is supported by the relative behavior of the mechanical tests performed at different heating rates.

\section{AA6061-T651 Microstructural Evolution}

AA6061-T651 is an Al-Mg-Si alloy strengthened by precipitation (or age) hardening. Al-Mg-Si alloys are primarily strengthened by precipitation of the metastable $\beta^{\prime \prime}$ phase. The alloying elements $(\mathrm{Mg}$ and $\mathrm{Si})$ are soluble at elevated temperatures and have reducing solubility with decreasing temperature. This allows for formation of a supersaturated solid solution (SSSS) with more $\mathrm{Mg}$ and Si dissolved in the $\alpha$-Al matrix than is thermodynamically possible at ambient conditions. Interactions between dislocations and precipitates formed by aging after solutionizing significantly strengthens the alloy. Several types of interactions occur depending on precipitate size and coherency - dislocations cut, bypass, or accumulate in tangles around precipitates [6]. AA6061-T651 constitutive behavior, specifically yield strength and work-hardening capacity, is dependent on the type of precipitate-dislocation interaction. The peak artificial aging condition (T6xx) investigated in this research is associated with an optimal precipitate state which achieves a high yield strength, good work-hardening characteristics, and maintains sufficient ductility.

The Al-Mg-Si precipitation sequence, including precipitate morphology and strengthening contribution, has been extensively researched [16-18]. Murayama and Hono [16] focused on the precipitation sequence from SSSS to precipitate precursors (Guinier-Preston zones) to the primary strengthening phase, $\beta^{\prime \prime}$. Edwards, et al. [17] proposed a generally accepted precipitation sequence for Al-Mg-Si alloys (Fig. 9). An overview of the Mg-Si containing phases in the Al-Mg-Si precipitation sequence is provided by Marioara, et al. [18]. The bulk of precipitation sequence research, such as that by Murayama and Hono [16], focuses on the precursors and factors affecting $\beta^{\prime \prime}$ phase precipitation. AA6061-T651 is peak artificially aged and, therefore, comes with the $\beta^{\prime \prime}$ phase in its peak precipitated state. Thus, the $\beta^{\prime \prime}$ phase in the precipitation sequence (Fig. 9) may be considered the incipient phase for subsequent precipitate evolution.

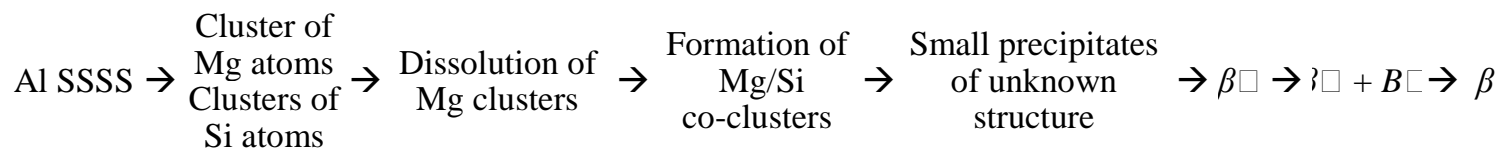

Fig. 9. AA6061-T651 (Al-Mg-Si) precipitation sequence [17].

$\mathrm{Al}-\mathrm{Mg}-\mathrm{Si}$ precipitate evolution has been shown as thermal history dependent during artificial aging [19], [20]. Differential scanning calorimetry (DSC) is typically used to evaluate the precipitation sequence including time-temperature evolution of the phases. In this research, AA6061-T651 phase evolution was qualitatively analyzed using the specific heat curve as measured by DSC. Available references [16-20] were used to examine precipitate evolution. The specific heat curve (Fig. 10) was measured using a 
Netzsch STA $449 \mathrm{~F} 1$ Jupiter at a heating rate of $20^{\circ} \mathrm{C} / \mathrm{min}$. The DSC specimen was solution heat treated at $550^{\circ} \mathrm{C}$ for $1.5 \mathrm{~h}$, quenched in water, and held at ambient conditions for $2.5 \mathrm{~h}$ prior to testing.

Table 1. Overview of Mg-Si phases in Al-Mg-Si alloy (AA6082) [18].

\begin{tabular}{|l|l|l|l|}
\hline Phase & \multicolumn{1}{|c|}{ Chemistry } & \multicolumn{1}{|c|}{ Morphology } & Coherency \\
\hline $\mathrm{GP}$ & $\mathrm{Si} / \mathrm{Mg}>1$ & Almost spherical, $1-2 \mathrm{~nm}$ & \\
\hline$\beta^{\prime \prime}$ & $\mathrm{Mg}_{5} \mathrm{Si}$ & Needles, up to $40 \times 40 \times 350 \AA$ & Coherent \\
\hline$\beta^{\prime}$ & $\mathrm{Mg}_{1.7} \mathrm{Si}$ & Ribbons, several $\mu \mathrm{m}$ long & Semi-coherent \\
\hline$\beta$ & $\mathrm{Mg}_{2} \mathrm{Si}$ & Plates or cubes, up to $10-20 \mu \mathrm{m}$ diameter & Non-coherent \\
\hline$B^{\prime}$ & $\mathrm{Mg} / \mathrm{Si} \approx 1$ & Ribbons, up to $1 \mu \mathrm{m}$ long & Semi-coherent \\
\hline
\end{tabular}

The specific heat curve (Fig. 10) may be analyzed in terms of precipitate evolution [17], [18] to elucidate the mechanisms governing AA6061-T651 residual constitutive behavior (Figs. 3c,d and Fig. 4). The reactions $\left(\mathrm{A}-\mathrm{C}\right.$ ) below the large exothermic peak (D) at $265^{\circ} \mathrm{C}$ are primarily of concern for artificial aging and have little impact on residual constitutive behavior. The $\beta^{\prime \prime}$ phase (corresponding to exothermic peak D at $265^{\circ} \mathrm{C}$ ) is associated with the peak-aged condition (T6xx). Therefore, heating to this temperature should result in no significant changes in constitutive behavior; measured behavior agrees with this assertion. As the temperature increases, the needle-like $\beta^{\prime \prime}$ coarsens to ribbon-like $\beta^{\prime}$ and $B^{\prime}$ precipitates at exothermic peak $\mathrm{E}\left(300^{\circ} \mathrm{C}\right)$. Residual property reduction $\left(200-400^{\circ} \mathrm{C}\right)$ occurs due to precipitate evolution past $\beta^{\prime \prime}$ (overaging) and is mostly attributable to semi-coherent $\beta^{\prime}$ formation [17]. The $\beta^{\prime}$ and $B^{\prime}$ precipitates further coarsen through exothermic peak $\mathrm{F}\left(360^{\circ} \mathrm{C}\right)$ to form the meta-stable, non-coherent $\beta$ phase. The $\beta$ phase is the only precipitate phase that can be imaged with an optical microscope [6], as shown for the $400^{\circ} \mathrm{C}$ exposure in Fig. 11. The final endothermic reaction (peak $\mathrm{G}$ at $450^{\circ} \mathrm{C}$ ) signifies dissolution of the $\beta$ phase [17]. This is evidenced as the disappearance of the high precipitate density from Fig. 11b to 11c. Doan, et al. [19] and Gaber, et al. [20] performed similar DSC studies at multiple heating rates and, as expected, lower and higher heating rates resulted in lower and higher temperature reaction peaks, respectively.

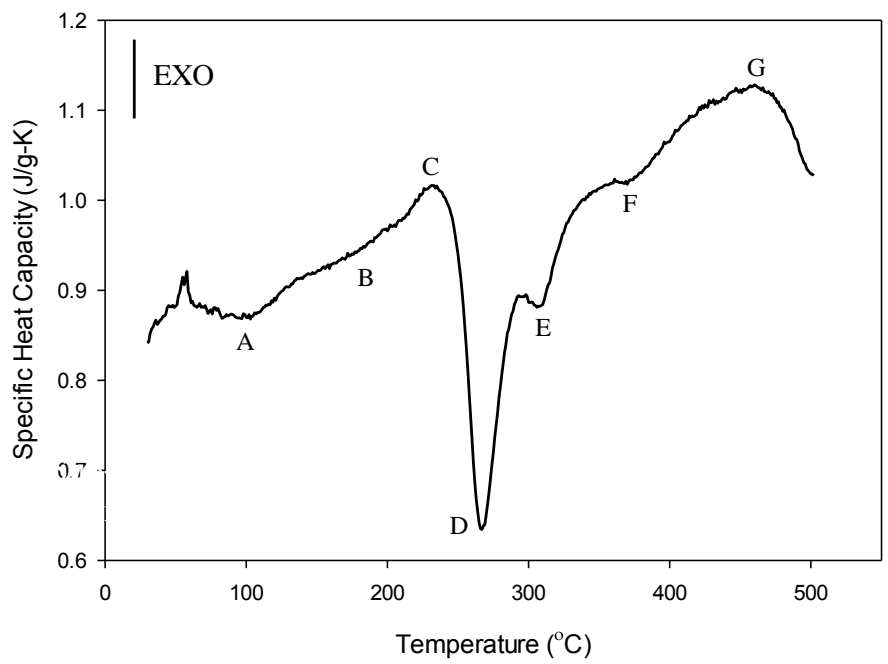

Fig. 10. AA6061-T651 specific heat measured using DSC at $20^{\circ} \mathrm{C} / \mathrm{min}$.

The thermal history dependent evolution of AA6061-T651 residual constitutive behavior is governed by precipitate evolution. The time-temperature heating dependence of residual constitutive behavior is significant for specimens exposed to 300 and $400^{\circ} \mathrm{C}$. This is readily explained by the kinetic dependence of precipitate evolution [19], [20], which governs constitutive behavior. The coarsening of $\beta^{\prime \prime}$ to $\beta^{\prime}$ is the principal cause of yield strength reduction in Fig. 4a [17]. This also causes increased work-hardening as observed in Fig. 3c which is a result of a change in the precipitate-dislocation interaction. Dislocations are forced to bypass $\beta^{\prime \prime}$ precipitates thereby causing a significant increase in strength. Coarsening of $\beta^{\prime \prime}$ to $\beta^{\prime}$ causes dislocation entanglement on the precipitates thereby promoting additional work hardening [6]. This is further exemplified by the increase in work hardening from 300 to $400^{\circ} \mathrm{C}$ due to further coarsening of the 
$\beta^{\prime}$ phase. Further heating to $500^{\circ} \mathrm{C}$ causes partial dissolution of the $\beta$ phase resulting in work hardening similar to that of the solid-solution hardened AA5083-H116 (Fig. 3a).

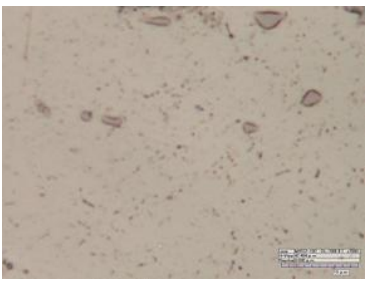

(a)

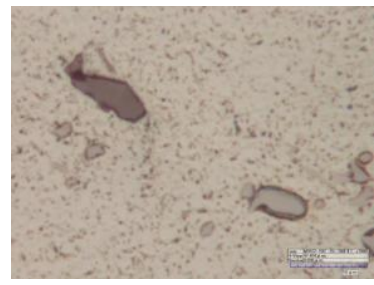

(b)

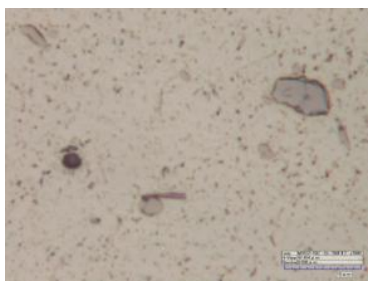

(c)

Fig. 11. AA6061-T651 optical micrographs (7000x) for (a) as-received and (b) $400^{\circ} \mathrm{C}$ and (c) $500^{\circ} \mathrm{C}$ exposed specimens.

In summary, AA6061-T651 residual constitutive behavior after elevated temperature exposure is governed by precipitate morphology. Coarsening of the as-received $\beta^{\prime \prime}$ phase developed during peak artificial aging causes the evolution of the residual constitutive behavior. Precipitate evolution causes the precipitatedislocation interaction to change. Due to the fact that this interaction governs constitutive behavior it is this evolution which causes the evolution of constitutive properties. Precipitate evolution was also shown to be dependent on thermal history thereby causing the residual constitutive behavior to be thermal history dependent, as evidenced in Fig. 3c.

\section{CONCLUSIONS}

In this paper, the residual constitutive behavior of AA5083-H116 and AA6061-T651 aluminum alloys was investigated. Quasi-static, uniaxial tension tests were performed on specimens previously exposed to elevated temperature to simulate fire exposure. Specimens were exposed to elevated temperatures $(100-$ $\left.500^{\circ} \mathrm{C}\right)$ using an induction heater at controlled, linear heating rates $\left(5,25\right.$, and $\left.250^{\circ} \mathrm{C} / \mathrm{min}\right)$. The residual constitutive behavior was measured using strain gages and a stereoscopic digital image correlation system to provide accurate elasticity data and detailed plasticity data, respectively.

The residual constitutive behavior of the alloys was shown to evolve differently as a function of prior thermal history. AA5083-H116 undergoes a 57\% reduction in yield strength after exposure to $400^{\circ} \mathrm{C}$ for all tested heating rates. The majority of this reduction occurs between 300 and $400^{\circ} \mathrm{C}$. The work-hardening behavior is approximately maintained in the as-received state during mechanical property deterioration. AA6061-T651 experiences a $73 \%$ yield strength reduction from $200^{\circ} \mathrm{C}$ to $400^{\circ} \mathrm{C}$. The reduction over this temperature range is dependent on prior thermal history, specifically the heating rate. AA6061 workhardening behavior evolves significantly as a function of prior thermal exposure.

The microstructural strengthening mechanisms were investigated in an effort to understand the mechanisms governing residual constitutive behavior, specifically thermal history dependence. AA5083-H116 residual constitutive behavior is primarily governed by evolution of grain morphology by recrystallization, which is kinetically-dependent on prior thermal exposure. The work-hardening behavior is primarily determined by solid-solution strengthening, which is largely unaffected by prior thermal exposure. AA6061-T651 residual constitutive behavior is governed by precipitates evolution resulting in a changing in the precipitate-dislocation strengthening interaction. The evolution of this interaction also causes the increases work-hardening capacity of the alloy. The heating rate dependence of the residual constitutive behavior is elucidated in terms of the well-established and studied kinetic, time-temperature dependent evolution of the governing microstructural strengthening mechanisms, specifically through recrystallization and precipitate coarsening.

The fundamental understanding of residual constitutive behavior, and the mechanisms that govern its evolution, provide a tool with which to assess an aluminum structure damaged by fire. The manner in which the residual behavior was quantified - in terms of its time-temperature, kinetic dependence - allows for application of this knowledge across a broad spectrum of fires and is not limited to that studied. Additionally, it is expected the residual mechanical behavior of aluminum alloys may be classified by their respective strengthening method, i.e., strain or precipitate hardening. For example, strain hardened alloys are expected to have similar behavior to the plateau-like reduction in AA5083-H116 yield strength (Fig. 
4a). This reduction is the result of recrystallization which modifies the strengthening mechanisms induced by strain hardening. However, it is important to recognize the kinetic details of property reduction are specifically dependent on the alloy system and its temper. This knowledge also provides a concrete foundation with which to assess fire damage and intelligently repair the structure, thereby saving unnecessary costs and time.

\section{ACKNOWLEDGEMENTS}

The authors would like to thank the Office of Naval Research for funding this work through Grant No. N00014-10-1-0690 with Dr. Steven Turner and Dr. Luise Couchman as Technical Monitors. The authors would also like to thank Yanyun Chen for TEM imaging.

\section{REFERENCES}

[1] Kandare, E., Feih, S., Kootsookos, A., Mathys, Z., Lattimer, B.Y., and Mouritz, A.P., (2010) Creep-based life prediction modelling of aluminium in fire, Materials Science and Engineering: A 257: 1185-1193, http://dx.doi.org/10.1016/j.msea.2009.10.010

[2] CEN. Eurocode 9 - Design of aluminum structures - Part 1-2: Structural fire design, European Committee for Standardization 2007, Brussels, ENV 1999-1-2:2007.

[3] Matulich, R.D., Post-fire mechanical properties of aluminum alloys and aluminum welds. Master's Thesis 2011. Virginia Polytechnic Institute \& State University.

[4] Qiang, X., Bijlaard, S.K., and Kolstein, H., (2012) Post-fire mechanical properties of high strength structural steels S460 and S690, Engineering Structures 35: 1-10, http://dx.doi.org/10.1016/j.engstruct.2011.11.005

[5] Huskins, E.L., Cao, B., and Ramesh, K.T., (2010) Strengthening mechanisms in an Al-Mg alloy, Materials Science and Engineering: A 527: 1292-1298, http://dx.doi.org/10.1016/j.msea.2009.11.056

[6] Dieter, G., Mechanical Metallurgy, $2^{\text {nd }}$ Edition, McGraw-Hill, New York, 1976.

[7] Butt, M., and Feltham, P., (1993) Solid-solution hardening, Journal of Materials Science 28: $2557-$ 2576, http://dx.doi.org/10.1007/BF00356192

[8] Clausen, A., Borvik, T., Hopperstad, O., and Benallal, A., (2004) Flow and fracture characteristics of aluminium alloy AA5083-H116 as function of strain rate, temperature and triaxiality, Materials Science and Engineering: A 364: 260-272, http://dx.doi.org/10.1016/j.msea.2003.08.027

[9] Popovic, M., and Romhanji, E., (2008) Characterization of microstructural changes in an Al$6.8 \mathrm{wt} . \% \mathrm{Mg}$ alloy by electrical resistivity measurements, Materials Science and Engineering: A 492: 460-467, http://dx.doi.org/10.1016/j.msea.2008.04.001

[10] Doherty, R.D., Hughes, D.A., Humphreys, F.J., Jonas, J.J., Jensen, J., Kassner, M.E., King, W.E., McNelley, T.R., McQueen, H.J., and Rollett, A.D., (1997) Current issues in recrystallization: a review, Materials Science and Engineering: A 238: 219-247, http://dx.doi.org/10.1016/S0921$\underline{\text { 5093(97)00424-3 }}$

[11] Sandstrom, R., and Lindgren, I., (1981) The combined influence of recrystallization and recovery on stress-strain curves in aluminium, Materials Science and Engineering: A 47: 217-228, http://dx.doi.org/10.1016/0025-5416(81)90048-3

[12] Last, H.R., and Garrett, R.K., (1996) Mechanical behavior and properties of mechanically alloyed aluminum alloys, Metallurgical and Materials Transactions A 27: 737-745, http://dx.doi.org/10.1007/BF02648961

[13] ASTM Standard E112, 2012, Standard test methods for determining average grain size, ASTM International, West Conshohocken, PA, http://dx.doi.org/10.1520/E0112-12 
[14] Kwon, O., and DeArdo, A.J., (1990) On the recovery and recrystallization which attend static softening in hot-deformed copper and aluminum, Acta Metallurgica et Materialia 38: 41-54, http://dx.doi.org/10.1016/0956-7151(90)90133-2

[15] Vandermeer, R.A., and Juul Jensen, D., (2001) Microstructural path and temperature dependence of recrystallization in commercial aluminum, Acta Materialia 49: 2083-2094, http://dx.doi.org/10.1016/S1359-6454(01)00074-X

[16] Murayama, M., and Hono, K., (1999) Pre-precipitate clusters and precipitation processes in AlMg-Si alloys, Acta Meterialia 47: 1537-1548, http://dx.doi.org/10.1016/S1359-6454(99)00033-6

[17] Edwards, G., Stiller, K., Dunlop, G., and Couper, M., (1998) The precipitation sequence in AlMg-Si alloys, Acta Materialia 46: 3893-3904, http://dx.doi.org/10.1016/S1359-6454(98)00059-7

[18] Marioara, C., Andersen, S., Jansen, J., and Zandbergen, H., (2001) Atomic model for GP-zones in a 6082 Al-Mg-Si system, Acta Materialia 49: 321-328, http://dx.doi.org/10.1016/S13596454(00)00302-5

[19] Doan, L.C., Ohmori, Y., and Nakai, K., (2000) Precipitation and dissolution reactions in a 6061 aluminum alloy, JIM, Materials Transactions 41: 300-305

[20] Gaber, A., Gaffar, M.A., Mostafa, M.S., and Abo Zeid, A.F., (2006) Investigation of developed precipitates in Al-1.1 wt-\% $\mathrm{Mg}_{2} \mathrm{Si}$ balanced alloy by DSC and SEM techniques, Materials Science and Technology 22: 1483-1488, http://dx.doi.org/10.1179/174328406X100707 